\title{
Working Memory Performance Under Stress
}

\section{Do Women Profit From Cortisol Release, Whereas Men Don't? A Study on Healthy Older Adults}

\author{
Petra Luers ${ }^{1,2}$, Malgorzata Schloeffel ${ }^{2,3}$, and Jens C. Prüssner ${ }^{1}$ (1) \\ 1Department of Psychology, University of Konstanz, Konstanz, Germany \\ 2Department of Biological and Clinical Psychology, University of Trier, Trier, Germany \\ ${ }^{3}$ Section of Health Care Research and Rehabilitation Research, Medical Center-University of Freiburg, Faculty of Medicine, University of \\ Freiburg, Germany
}

\begin{abstract}
Acute stress and chronic stress change the physiology and function of the individual. As one facet, stress and its neuroendocrine correlates - with glucocorticoids in particular - modulate memory in a concerted action. With respect to working memory, impairing effects of acute stress and increased levels of glucocorticoids could be expected, but empirical evidence on moderating effects of cortisol on working memory is ambiguous in human studies. In the current study, we thus aimed to investigate cortisol stress responses and memory performance. Older men and women (32 men, 43 women, aged 61-67 years) underwent the Trier Social Stress Test (TSST) and performed the 2-back task before and after exposure to acute stress. In line with theoretical assumptions, we found that higher cortisol stress responses led to a decline of working memory performance in men. However, the opposite was evident for women, who appeared to benefit from higher stress responses. This effect was evident for accuracy, but not for reaction time. In conclusion, cortisol might mediate working memory alterations with stress in a sex-specific manner in older people. Possible mechanisms and causes for these sex differences put a focus on endocrine changes in the aging population that might lead to differential effects across the lifespan.
\end{abstract}

Keywords: working memory, stress, cortisol, sex-specific effects, TSST

Stress causes physiological and endocrine changes throughout the organism, which lead to numerous behavioral and functional changes in the individual (D. H. Hellhammer \& Hellhammer, 2008; McEwen, 2004). In the central nervous system, stress affects memory in a concerted way of action (de Quervain, Schwabe, \& Roozendaal, 2017; Hermans, Henckens, Joëls, \& Fernández, 2014; Roozendaal \& McGaugh, 2011). One relevant subsystem in this framework is working memory, i.e., the limited capacity system to temporarily store, maintain, and update information (Baddeley, 2003). Stress may acutely impair working memory via glucocorticoid actions on the prefrontal cortex (PFC) and further brain regions, given concomitant arousal and noradrenergic transmission of the basolateral amygdala (de Quervain, Aerni, Schelling, \& Roozendaal,
2009). Whereas elaborate animal models have supported this assumption, studies in humans about the mediating role of cortisol have produced mixed findings. Although, according to a meta-analysis, acute stress indeed impairs working memory performance, no mediating role of cortisol was observed across 34 studies (Shields, Sazma, \& Yonelinas, 2016). Notably, this meta-analysis was based on between-group approaches, which compared memory performance between a stressed and a nonstressed group. While such approaches are both meaningful and important for understanding general effects of stress on memory, they do not allow for studying patterns of intraindividual variability. However, both working memory changes under stress and cortisol stress responses considerably differ between people (Bogdanov \& Schwabe, 2016; Hellhammer, Meinlschmidt, \& Pruessner, 2018; Kudielka, Hellhammer, \& Wüst, 2009). Studies analyzing individual cortisol stress responses and their relation with poststress memory performance yield heterogeneous results, with positive (van Ast et al., 2016), negative (Oei, Everaerd, Elzinga, van Well, \& Bermond, 2006; Qin, Hermans, van Marle, Luo, \& 
Fernandez, 2009; Schoofs, Preuß, \& Wolf, 2008; Smeets, Jelicic, \& Merckelbach, 2006), or insignificant (Pulopulos et al., 2015; Zandara et al., 2016) findings. Inconsistencies might either be due to study characteristics, such as different working memory tasks, magnitude of Hypothalamuspituitary-adrenal (HPA) axis activation achieved by the stress manipulation, and the population studied, or due to missing individual baseline assessments. Complementing these points, limited statistical power might prevent effects to be observed in individual studies even though they are present in the population. Within-group analyses can overcome this limitation as they allow for an estimation of intraindividual trajectories, but studies are scarce to date (Luettgau, Schlagenhauf, \& Sjoerds, 2018; Pulopulos et al., 2015; Stauble, Thompson, \& Morgan, 2013; Zandara et al., 2016) and typically work with healthy young samples, even though assessment of working memory is sometimes performed three times, to differentiate adrenergic from glucocorticoid effects on working memory (Elzinga \& Roeloefs, 2005).

To address a gap in the literature, we here examined both changes in working memory performance and cortisol responses with stress in an elderly community sample using a within-group design: Healthy elderly subjects first performed a working memory task prestress, then underwent a laboratory stress task, and subsequently performed the memory task again. We used the $n$-back task, well-established and widely used working memory tasks requiring high cognitive demands (Conway et al., 2005; Kirchner, 1958; Shields et al., 2016). As stress effects have been mostly shown for higher task difficulties, we here chose the 2-back condition. The $n$-back robustly activates the PFC (Owen, McMillan, Laird, \& Bullmore, 2005), although this effect appears to be declining with age (Yaple, Stevens, \& Arsalidou, 2019). For stress manipulation, we used the Trier Social Stress Test (TSST), a standard laboratory stress induction method, robustly eliciting cortisol responses (Dickerson \& Kemeny, 2004; Kirschbaum, Pirke, \& Hellhammer, 1993; Kudielka, Hellhammer, \& Kirschbaum, 2007).

In line with theoretical assumptions and with the majority of previous studies, we expected that individual cortisol responses to stress were negatively related to alterations in memory performance. We further expected a robust cortisol response to stress (Otte et al., 2005) with higher responses in men than in women (Kudielka \& Kirschbaum, 2005).

\section{Materials and Methods}

\section{Participants and Recruitment}

The study enrolled $N=75$ subjects $(n=32$ men, $n=43$ women), aged 61-67 years. The mean age was 64.1 years
(SEM \pm 0.2 years), and the mean body mass index (BMI) was $27.5 \mathrm{~kg} / \mathrm{m}^{2}$ (SEM \pm 0.5$)$. Men and women did not differ in age $\left(t_{d f=73}=-1.06, p=.292, d^{\prime}=-.24\right)$ and BMI $\left(t_{d f=73}=-1.5, p=.130, d^{\prime}=-.36\right)$. Eight subjects ( $n=5$ women, $n=3$ men) habitually smoked cigarettes, and all other participants were nonsmokers. Analyzing the data with and without smokers did not alter the results; hence, smokers were not excluded. $N=44$ participants (59\%) took medication ( $n=22$ men, $n=22$ women). We allowed for medication intake apart from medication types specified below as being common for the age group studied, and we statistically controlled for medication effects. Originally, the sample size was $n=82$ in total, and data of seven persons had to be eliminated - due to $n=3$ subjects reporting fear for injections/problematic blood drawings, $n=1$ for an unexpected fire alarm shortly before the TSST, $n=1$ for refusing to complete the working memory task, and $n=2$ persons with performance at chance level, casting doubts that these subjects either lacked motivation or had not properly understood the task.

The study was part of a research grant on stress vulnerability (DFG grant HE 1013/21-1). Subjects had participated in two earlier study parts, which involved completing questionnaires at home, collecting salivary cortisol samples with and without dexamethasone intake at home, and visiting the laboratory once for both a medical check and an interview on early life stress (the results will be reported elsewhere). Participants of the present study were recruited by phone and received both oral and written study information before reporting to the laboratory. All subjects gave written informed consent. The study was approved by the State Chambers of Physicians (Landesärztekammer Rheinland-Pfalz) and was performed in line with the Declaration of Helsinki.

Exclusion criteria for the current study were an impaired status of health, untreated hypertension or diabetes mellitus, intake of glucocorticoid, immunosuppressive, antidepressant, or antidiabetic medication, an ongoing therapy of a mental disorder, and prior participation in a study involving the TSST. Medication reported by participants not leading to exclusion from the current study included $\beta$-blockers, $\alpha$-antagonists, acetylcholineesterase inhibitors, thyroid medication, aspirin, and calcium antagonists. Depression and anxiety scores were checked by questionnaire, and all subjects were below clinical cutoffs.

\section{Working Memory: 2-Back Task}

In this study, we used the 2-back version of the $n$-back paradigm with consonant letters as stimuli. The 2-back was programmed in E-Prime v1.2 (Psychology Software Tools, Inc.) and displayed on a laptop. Subjects had to push one of 
the two possible buttons ("yes" or "no," marked in green and red, respectively) on the laptop keyboard with the index and middle finger of their dominant hand to indicate whether the currently presented stimulus was the same as the one presented two trials previously.

Acquisition phase: To familiarize subjects with the task, instructions were displayed on a laptop, and a study leader explained the task in a standardized manner, allowing for subsequent questions. Subjects then absolved practice trials $(2 \times 15$ stimuli) until $80 \%$ accuracy was obtained. Queries were allowed during that phase. Testing trials: Pre- and poststress testing trials consisted of two blocks per session $(2 \times 26$ stimuli). Poststress testing was preceded by a practice trial of $2 \times 8$ stimuli to remind subjects of the task. The stimuli were displayed for $500 \mathrm{~ms}$ with an interstimulus interval of 2,500 ms. In each block, the first two stimuli were not analyzed, and within the remaining trials, target stimuli were presented randomly with a probability of $33 \%$. Five response options were coded (hit, false alarm, correctly rejected, missed hit, and no response within interstimulus interval).

\section{Stress Induction: Trier Social Stress Test}

We conducted the TSST as described in Kirschbaum et al. (1993). At the core, the TSST induces psychosocial stress through a 10-min anticipation period, followed by a 5 -min impromptu oral presentation and a 5-min mental arithmetic in front of a two-person mixed gender panel. Panel members were about the same age as study participants and had completed an in-house TSST training to perform their roles in a standardized manner.

\section{Procedure}

Subjects were instructed to refrain from doing heavy sports and from drinking alcohol the evening before coming to the laboratory and at the testing day. Participants were furthermore asked to eat a regular meal at the testing day but to refrain from eating and drinking $2 \mathrm{hr}$ before reporting to the laboratory. Sessions started between 1:00 p.m. and 4:00 p.m.

After arrival, we accommodated the subject in a separate room equipped with a desk, a medical couch, and a poseur table and introduced him/her to the procedure. The study physician then undertook a medical examination and placed an indwelling catheter (Vasofix Safety, Braun Melsungen AG, $18 \mathrm{G}$ ) for repeated blood drawings (results reported elsewhere) into the participant's antecubital vein at $55 \mathrm{~min}$ before stress. Thirty-five minutes before the TSST, the participant completed the digit span backwards task (results will be reported elsewhere), then started the 2-back acquisition phase (approximately 30 min before the TSST), and absolved the 2-back prestress trials (until $15 \mathrm{~min}$ before the TSST). If participants had absolved the testing trials early, the d2-test was offered as a filler task (Brickenkamp, 1981). Ten minutes before the TSST, the participant completed questionnaires on his actual subjective stress level while standing. The TSST was conducted in a separate room. Afterward, the participant was led back to the initial room and completed a brief questionnaire on his/her mood while standing. Five minutes after the TSST, the participant was asked to sit down again, and the digit span backwards task was reassessed. Ten minutes after the TSST, performance on the 2-back was reassessed. Twenty minutes after the TSST, the participants started completing a set of questionnaires. Ninety minutes after the TSST, the study leader debriefed the participant. Finally, the study team thanked the participant for supporting this research study, and the participant received a financial compensation of $60 €$.

\section{Salivary Cortisol: Sampling, Preanalytics, and Analysis}

Saliva was collected with Salivettes ${ }^{\circ}$ (Sarstedt, Nuembrecht, Germany) at $-35,-15,-1,+1,+10,+20$, and $+90 \mathrm{~min}$ relative to the onset of the TSST. Salivettes were kept at room temperature until the end of the testing session and were stored thereafter at $-20^{\circ} \mathrm{C}$ until analysis. All biochemical analyses were performed by technicians at the University of Trier biochemical laboratory. Salivary cortisol was analyzed with an in-house time resolved dissociation-enhanced lanthanide fluorescence immunoassay (DELFIA). Interassay and intraassay coefficients of variance were both below $10 \%$.

\section{Data Preparation}

We assessed working memory performance before and after stress as accuracy [mean \%correct responses (CR)] and reaction time [mean reaction time (RT) for CR]. ${ }^{1}$ To assess changes in working memory performance, we calculated the difference between individual accuracy and reaction time values poststress and prestress as $\Delta \mathrm{CR}=\% \mathrm{CR}$ post $-\% \mathrm{CR}$ pre and $\Delta \mathrm{RT}=\mathrm{RTpost}-\mathrm{RTpre}$.

\footnotetext{
1 The raw data files can be accessed online (http://dx.doi.org/10.23668/psycharchives.3015).
} 
Furthermore, the change in cortisol was calculated as the difference between individual peak values after the TSST and basal levels at $1 \mathrm{~min}$ prior to the TSST as $\Delta$ cort $=$ peak cortisol levels poststress - prestress cortisol levels.

\section{Statistical Approach}

Statistical analyses were performed with IBM SPSS Statistics Version 25. For analyzing stress responses and alterations in working memory over time, we calculated general linear models (GLMs) with repeated measures and applied Greenhouse-Geisser corrections where appropriate and entered sex as a group factor. Furthermore, medication status (yes/no) was introduced as a group factor to test whether participants taking medication differed from medication-free participants. To analyze the relation between individual changes in working memory, cortisol responses, and sex, $\Delta \mathrm{CR}$ und $\Delta \mathrm{RT}$ were separately introduced as continuous variables into the GLM with repeated measures on cortisol. In this model, the three-way interaction Cortisol $\times$ Sex $\times$ Delta working memory, all two-way interactions and main effects were included. Effect sizes are expressed as partial eta squares $\left(\eta_{\mathrm{p}}^{2}\right)$.

To compare our results with those of other studies, we furthermore calculated two-tailed Pearson correlations to investigate associations between working memory performance after stress and $\Delta$ cortisol for the sample as a whole, for women and men separately. All figures show mean values \pm SEM.

\section{Results}

\section{Stress Induction: Salivary Cortisol Responses}

As expected, the TSST elicited significant increases in salivary cortisol levels: In the overall sample, cortisol levels increased from $3.69 \mathrm{nmol} / \mathrm{L}$ prior to the TSST to peak values of $11.62 \mathrm{nmol} / \mathrm{L} 20 \mathrm{~min}$ after the TSST (Cortisol $\times$ Time: $\left.F_{d f=1.32 ; 94.03}=113.8, p<.001, \eta_{\mathrm{p}}^{2}=.62\right)$. Cortisol responses did not differ between men and women (interaction Cortisol $\times$ Sex: $F_{d f=1.32 ;} 94.03=.99, p=.344, \eta_{\mathrm{p}}^{2}=.01$, main effect sex $F_{d f=1,71}=.84, p=.362, \eta_{\mathrm{p}}^{2}=.01$; see Figure 1).

\section{Working Memory: Alterations in Accuracy and Reaction Time}

Working memory performance increased significantly from pre- to poststress in the overall sample: Both accuracy

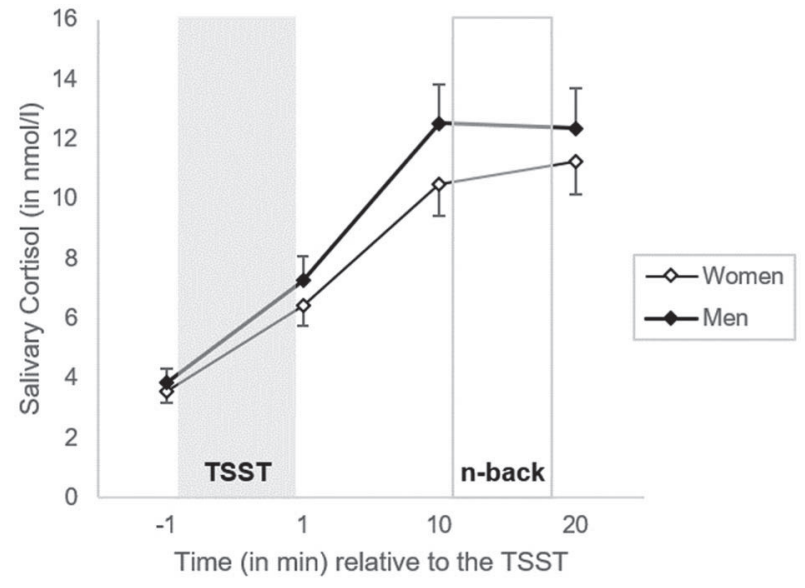

Figure 1. Salivary cortisol responses to the stress test. Cortisol levels significantly increase in men and women in response to the TSST (time of stress exposure corresponds to gray rectangle). The time of the $n$-back working memory task corresponds to the white rectangle. The $x$-axis shows the time in minutes relative to stressor onset, and the $y$-axis shows the salivary cortisol levels in $\mathrm{nmol} / \mathrm{L}$. Together, men $(n=32$, closed plaids) and women ( $n=43$, open plaids) responded with a significant increase to the TSST $(p<.001)$ but did not differ from each other in their response ( $p=.344$, details in the text). Error bars shown are standard error of mean.

(\%CR) and reaction time for CR improved. Accuracy increased from $88.2 \%$ in the prestress phase to $90.6 \%$ in the poststress testing phase $\left(\% \mathrm{CR} \times\right.$ Time: $F_{d f=1,71}=8.02$, $\left.p=.006, \eta_{\mathrm{p}}^{2}=.10\right)$. Reaction time decreased from $898.5 \mathrm{~ms}$ to $820.3 \mathrm{~ms}$ (Reaction time $\times$ Time: $F_{d f=1,71}=23.07, p<.001$, $\left.\eta_{\mathrm{p}}^{2}=.25\right)$. Changes in accuracy did not differ between men and women $\left(\% \mathrm{CR} \times\right.$ Sex: $F_{d f=1,71}=.01, p=.933, \eta_{\mathrm{p}}^{2}<.01$, main effect sex: $\left.F_{d f=1,71}=1.84, p=.180, \eta_{\mathrm{p}}^{2}=.03\right)$, nor did changes in reaction time (Reaction time $\times$ Sex: $F_{d f=1,71}=.00$, $p=.959, \eta_{\mathrm{p}}^{2}<.01$, main effect sex: $F_{d f=1,71}=.40, p=.532$, $\left.\eta_{\mathrm{p}}^{2}=.01\right)$.

Improvements were not uniform however, and interindividual changes for $\Delta \mathrm{CR}$ ranged from $-17 \%$ to $+17 \%$ and for $\Delta \mathrm{RT}$ from $-516.6 \mathrm{~ms}$ to $296.4 \mathrm{~ms}$, suggesting that some subjects deteriorated (Quartile 1 for $\Delta \mathrm{CR}$, Quartile 4 for $\Delta \mathrm{RT}$ ), while others improved. To illustrate these differences across subjects, quartiles of change for both accuracy and reaction time are shown in Figure E1 in the Electronic Supplementary Material, ESM 1.

\section{Individual Changes in Working Memory and Cortisol: Changes in Accuracy Correspond With Changes in Cortisol in a Sex-Specific Manner}

Intercorrelations between $\Delta$ cort and working memory performance poststress are shown in ESM 1, Tables E1a-c. 

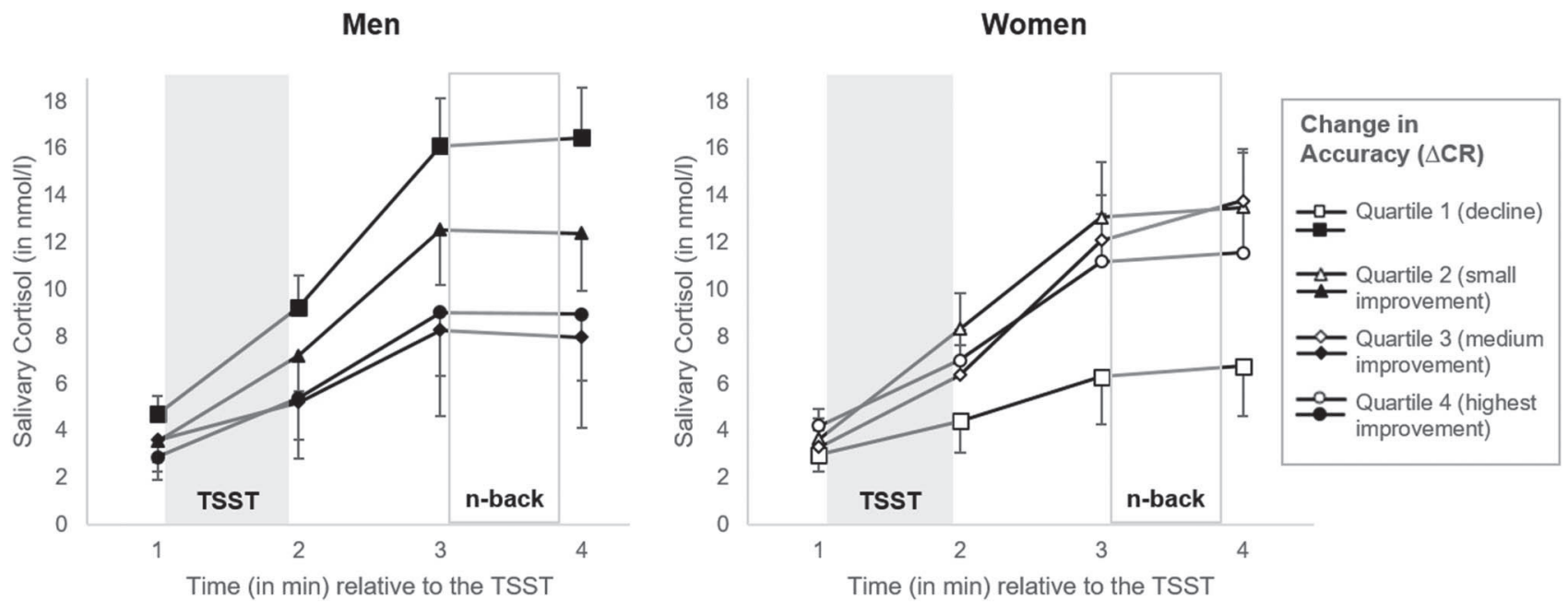

Figure 2. Men with the highest cortisol responses to stress decline in $n$-back performance, while this is the case for women with the lowest cortisol responses to stress. The left panel shows the relationship between change in accuracy in $n$-back performance from before to after stress ( $\Delta$ CR) and cortisol responses in men (all closed shapes, $n=32$ ). The right panel shows the relationship between change in accuracy in $n$-back performance from before to after stress $(\Delta \mathrm{CR})$ and cortisol responses in women (all open shapes, $n=43$ ). Squares denote decline in memory performance, triangles small improvements, plads medium improvement, and circles highest improvement. Time of stress exposure corresponds to gray rectangle, while the time of the $n$-back working memory task corresponds to the white rectangle. The $x$-axis shows the time in minutes relative to stressor onset, and the $y$-axis shows the salivary cortisol levels in nmol/L. Error bars shown are standard error of mean.

Changes in accuracy were differently associated with cortisol responses over time in men and women, evident by a significant three-way interaction of Cortisol $\times$ Sex $\times$ $\Delta \mathrm{CR}\left(F_{d f=1.36 ; 91.15}=6.81, p=.005, \eta_{\mathrm{p}}^{2}=.09\right)$. This was also mirrored by a significant two-way interaction of Sex $x$ $\Delta \mathrm{CR}$ over cortisol levels $\left(F_{d f}=1,67=7.61, p=.007\right.$, $\eta_{\mathrm{p}}^{2}=.10$ ). No further effects of $\Delta \mathrm{CR}$ were significant (all $F$-values $\leq 1.50, p$-values $\geq .230$, all $\left.\eta_{\mathrm{p}}^{2} \leq .02\right)$. As seen in the GLM model before, alterations in cortisol levels remained highly significant (Cortisol $\times$ Time: $F_{d f=1.31 ; 91.15}=108.53$, $p<.001 \eta_{\mathrm{p}}^{2}=.62$ ). To illustrate the three-way interaction between changes in cortisol, changes in working memory, and sex, Figure 2 shows cortisol alterations stratified for $\Delta \mathrm{CR}$ quartiles for men and women separately. As can be seen in Figure 2, while women who deteriorated in the 2-back showed the lowest cortisol responses, men who deteriorated in the 2-back showed the highest cortisol response. Results further suggest a dose-response effect of cortisol on 2-back performance in the opposite direction across the sexes although the relationship is not strictly linear.

For reaction time, no such associations were evident

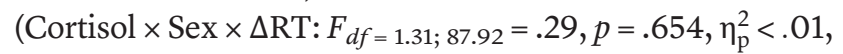
Sex $\times \Delta$ RT: $\left.F_{d f=1,67}=.00, p=.965, \eta_{\mathrm{p}}^{2}<.01\right)$. Except for a significant main effect of Reaction time $\times$ Time within subjects $\left(F_{d f}=1.31,87.92=76.75, p<.001, \eta_{\mathrm{p}}^{2}<.53\right)$, as reported before, no further effects were significant in this model.

No significant effects for medication status were evident in any analysis conducted, neither as main effects nor interactions (all $F$-values $\leq F=2.12, p \geq .150$, all $\eta_{p}^{2} \leq .03$ ). To finally check for medication effects, all analyses reported were rerun in the subsample not taking any medication $(N=31)$. Although \%CR changes over time only resulted in an overall tendency toward improvement $\left(F_{d f=1,29}=2.91, p=.099, \eta_{\mathrm{p}}^{2}<.09\right)$, the structure of further results principally remained the same. Although $\Delta \mathrm{CR}$ and reaction time are correlated with each other, it can be argued that applying corrections for multiple comparisons, to control for the number of performed tests, would be adequate. Using the more conservative Bonferroni correction, our significant results of a three-way interaction of Cortisol $\times$ Sex $\times \Delta$ CR and significant two-way interaction of Sex $\times \Delta$ CR over cortisol levels remain, as does the significant main effect of Reaction time $\times$ Time within subjects (all $p<.05)$.

\section{Discussion}

We here report that individual changes in working memory performance were associated with cortisol stress responses in a group of older adults. This relation, however, was sex-specific. In line with theoretical assumptions, cortisol stress responses were negatively linked with accuracy in men: Subjects with high cortisol responses showed accuracy impairments, while subjects with low- to mediate-level responses demonstrated graded accuracy improvements. In women, cortisol responses were 
positively linked with accuracy instead, with low cortisol responses corresponding to accuracy impairments. This relation was evident for 2-back accuracy, but not for reaction time.

The theoretical framework on stress- and glucocorticoidrelated impairments of working memory performance initially did not include predictions relating to sex differences or changes across the lifespan (Roozendaal \& McGaugh, 2011), but findings with regard to these factors have been emerging in recent years (de Quervain et al., 2017; Frick, Kim, Tuscher, \& Fortress, 2015; Hidalgo, Pulopulos, \& Salvador, 2019). In our sample, postmenopausal women were involved. Principally, estrogens may modulate stress-related effects on working memory (Herrera, Hodis, Mack, \& Mather, 2017; Ycaza Herrera \& Mather, 2015). Moreover, working memory capacity declines with age (Bopp \& Verhaeghen, 2020; Pliatsikas et al., 2019), and PFC involvement in working memory performance might be declining with increasing age (Yaple et al., 2019). Additionally, changes in HPA axis functioning and glucocorticoid receptors occur with age (Heffelfinger \& Newcomer, 2001). In sum, working memory might be differently regulated both in men as compared to women and in older as compared to younger people being exposed to stressful situations.

The only similar study using a within-design and involving older people of both sexes undergoing laboratory stress we found did not report a significant relation of cortisol stress responses and changes in working memory performance in men and women using the digit span backwards task (Pulopulos et al., 2015; Study 1). Two further within-design studies in young male students found an enhancing effect of individual cortisol responses using a change detection task (Stauble et al., 2013) and no support for a moderating role of cortisol using the $n$-back task (Luettgau et al., 2018). Except for the latter study, overall cortisol increases to stress were rather moderate. Possibly, the observed associations with cortisol might unwrap under higher magnitude of stress only. In addition, differences might be due to the memory tasks employed and the sample studied and remain open for further study.

Some between-group studies have looked at cortisol changes and working memory performance after stress (Oei et al., 2006; Qin et al., 2009; Schoofs et al., 2008; Smeets et al., 2006; van Ast et al., 2016). Notably, associations may differ when taking into account individual memory baseline levels. For instance, as reported before (Schoofs et al., 2008), we do observe negative correlations with cortisol changes and poststress reaction time in the 2-back task in men (see ESM 1, Tables E1a-c). However, our data show that prestress reaction time is similarly associated with cortisol responses, suggesting that both parameters might covary with a third factor instead of being causally related to each other. The exact nature of such a possible third factor remains to be elucidated, especially since we did not expect a correlation with prestress levels, and this is therefore an exploratory finding.

Contrary to our expectations, memory performance after stress was enhanced with regard to both reaction time and accuracy. However, our study was not designed to inform on general effects of stress on working memory performance, and due to the nature of the used study design, we cannot distinguish between practice and stress effects. Using a combined between-within-design comprising a counterbalanced control group would be more suited to address such questions (e.g., Bogdanov \& Schwabe, 2016; Luettgau et al., 2018). In line with previous studies, we thus interpret the observation of performance increase as a practice effect.

A limitation of the current study may be that we allowed for medication intake. We accepted medication intake as being common for the elderly sample studied. As a crude control measure, we statistically controlled for medication intake. Additionally, reanalyzing data in the medicationfree subset of subject essentially did not change the structure of results.

Generally, we consider it a strength of the study to involve older people of both sexes, which is a highly understudied sample to date. A possible further limitation is the exclusive use of the 2-back, as this caused a near ceiling performance poststress. Here, the additional employment of the 3-back would likely have caused a greater spread of performance, which might have allowed a better understanding of the cortisol increase/performance change relationship.

While this study contributes a first glance at sex differences in working memory in relation to stress levels, it is important to aim at understanding age- and sex-related processes in greater depth. As such, populations of both younger and middle-aged to older people should be included when investigating effects of stress on memory, and possibly, within stress research as a whole. Furthermore, a more frequent use of within-design studies might principally help elucidate the intricate picture of interindividual differences and might be highly informative to better understand stress-related changes on mind and body. 
ESM 1. Table: Intercorrelations between working memory parameters and change in cortisol. Figure: Changes in CR of the $n$-back working memory task before and after stress and reaction time.

\section{References}

Baddeley, A. (2003). Working memory: Looking back and looking forward. Nature Reviews Neuroscience, 4, 829-839. https://doi. org/10.1038/nrn1201

Bogdanov, M., \& Schwabe, L. (2016). Transcranial stimulation of the dorsolateral prefrontal cortex prevents stress-induced working memory deficits. Journal of Neuroscience, 36, 1429-1437. https://doi.org/10.1523/JNEUROSCI.3687-15.2016

Bopp, K. L., \& Verhaeghen, P. (2020). Aging and n-back performance: A meta-analysis. The Journals of Gerontology: Series B, 75, 229-240. https://doi.org/10.1093/geronb/gby024

Brickenkamp, R. (1981). Aufmerksamkeits-Belastungstest d2 [d2 test of attention]. Göttingen, Germany: Hogrefe Verlag.

Conway, A. R. A., Kane, M. J., Bunting, M. F., Hambrick, D. Z., Wilhelm, O., \& Engle, R. W. (2005). Working memory span tasks: A methodological review and user's guide. Psychonomic Bulletin \& Review, 12, 769-786. https://doi.org/10.3758/bf03196772

de Quervain, D. J.-F., Aerni, A., Schelling, G., \& Roozendaal, B. (2009). Glucocorticoids and the regulation of memory in health and disease. Frontiers in Neuroendocrinology, 30, 358-370. https://doi.org/10.1016/j.yfrne.2009.03.002

de Quervain, D., Schwabe, L., \& Roozendaal, B. (2017). Stress, glucocorticoids and memory: Implications for treating fearrelated disorders. Nature Reviews Neuroscience, 18(1), 7-19. https://doi.org/10.1038/nrn.2016.155

Dickerson, S. S., \& Kemeny, M. E. (2004). Acute stressors and cortisol responses: A theoretical integration and synthesis of laboratory research. Psychological Bulletin, 130, 355-391. https://doi.org/10.1037/0033-2909.130.3.355

Elzinga, B. M., \& Roeloefs, K. (2005). Cortisol-induced impairments of working memory require acute sympathetic activation. Behavioral Neuroscience, 119(1), 98-103. https://doi.org/10.1037/ 0735-7044.119.1.98

Frick, K. M., Kim, J., Tuscher, J. J., \& Fortress, A. M. (2015). Sex steroid hormones matter for learning and memory: Estrogenic regulation of hippocampal function in male and female rodents. Learning \& Memory, 22, 472-493. https://doi.org/10.1101/lm.037267.114

Heffelfinger, A. K., \& Newcomer, J. W. (2001). Glucocorticoid effects on memory function over the human life span. Development and Psychopathology, 13, 491-513. https://doi.org/10.1017/s0954579401003054

Hellhammer, D. H., \& Hellhammer, J. (2008). Neurobehavioral Medicine and Stress-related disorders. In A. Riecher-Roessler \& M. Steiner (Eds.), Stress. The brain-body connection (Vol. 174). Basel, Switzerland: Karger.

Hellhammer, D., Meinlschmidt, G., \& Pruessner, J. C. (2018). Conceptual endophenotypes: A strategy to advance the impact of psychoneuroendocrinology in precision medicine. Psychoneuroendocrinology, 89, 147-160. https://doi.org/10.1016/j.psyneuen. 2017.12.009

Hermans, E. J., Henckens, M. J. A. G., Joëls, M., \& Fernández, G. (2014). Dynamic adaptation of large-scale brain networks in response to acute stressors. Trends in Neurosciences, 37, 304-314. https://doi.org/10.1016/j.tins.2014.03.006

Herrera, A. Y., Hodis, H. N., Mack, W. J., \& Mather, M. (2017). Estradiol therapy after menopause mitigates effects of stress on cortisol and working memory. The Journal of Clinical Endocrinology \& Metabolism, 102, 4457-4466. https://doi.org/10.1210/jc. 2017-00825

Hidalgo, V., Pulopulos, M. M., \& Salvador, A. (2019). Acute psychosocial stress effects on memory performance: Relevance of age and sex. Neurobiology of Learning and Memory, 157, 48-60. https://doi.org/10.1016/j.nlm.2018.11.013

Kirchner, W. K. (1958). Age differences in short-term retention of rapidly changing information. Journal of Experimental Psychology, 55, 352-358. https://doi.org/10.1037/h0043688

Kirschbaum, C., Pirke, K.-M., \& Hellhammer, D. H. (1993). The "Trier Social Stress Test" - A tool for investigating psychobiological stress responses in a laboratory setting. Neuropsychobiology, 28(1-2), 76-81. https://doi.org/10.1159/000119004

Kudielka, B. M., Hellhammer, D. H., \& Kirschbaum, C. (2007). Ten years of research with the Trier Social Stress Test - revisited. In E. Harmon-Jones, \& P. Winkielman (Eds.), Social neuroscience: Integrating biological and psychological explanations of social behavior (pp. 56-83). New York, NY: Guilford Press.

Kudielka, B. M., Hellhammer, D. H., \& Wüst, S. (2009). Why do we respond so differently? Reviewing determinants of human salivary cortisol responses to challenge. Psychoneuroendocrinology, 34(1), 2-18. https://doi.org/10.1016/j.psyneuen.2008.10.004

Kudielka, B. M., \& Kirschbaum, C. (2005). Sex differences in HPA axis responses to stress: A review. Biological Psychology, 69(1), 113-132. https://doi.org/10.1016/j.biopsycho.2004.11.009

Luettgau, L., Schlagenhauf, F., \& Sjoerds, Z. (2018). Acute and past subjective stress influence working memory and related neural substrates. Psychoneuroendocrinology, 96, 25-34. https://doi. org/10.1016/j.psyneuen.2018.05.036

McEwen, B. S. (2004). Protection and damage from acute and chronic stress: Allostasis and allostatic overload and relevance to the pathophysiology of psychiatric disorders. Annals of the New York Academy of Sciences, 1032, 1-7. https://doi.org/10. 1196/annals.1314.001

Oei, N. Y. L., Everaerd, W. T. A. M., Elzinga, B. M., van Well, S., \& Bermond, B. (2006). Psychosocial stress impairs working memory at high loads: An association with cortisol levels and memory retrieval. Stress, 9, 133-141. https://doi.org/10.1080/ 10253890600965773

Otte, C., Hart, S., Neylan, T., Marmar, C., Yaffe, K., \& Mohr, D. (2005). A meta-analysis of cortisol response to challenge in human aging: Importance of gender. Psychoneuroendocrinology, 30(1), 80-91. https://doi.org/10.1016/j.psyneuen.2004.06.002

Owen, A. M., McMillan, K. M., Laird, A. R., \& Bullmore, E. (2005). Nback working memory paradigm: A meta-analysis of normative functional neuroimaging studies. Human Brain Mapping, 25(1), 46-59. https://doi.org/10.1002/hbm.20131

Pliatsikas, C., Veríssimo, J., Babcock, L., Pullman, M. Y., Glei, D. A., ... Ullman, M. T. (2019). Working memory in older adults declines with age, but is modulated by sex and education. Quarterly Journal of Experimental Psychology, 72, 1308-1327. https://doi. org/10.1177/1747021818791994

Pulopulos, M. M., Hidalgo, V., Almela, M., Puig-Perez, S., Villada, C., \& Salvador, A. (2015). Acute stress and working memory in older people. Stress, 18, 178-187. https://doi.org/10.3109/10253890. 2015.1004538

Qin, S., Hermans, E. J., van Marle, H. J. F., Luo, J., \& Fernandez, G. (2009). Acute psychological stress reduces working memory-related activity in the dorsolateral prefrontal cortex. Biological Psychiatry, 66, 25-32. https://doi.org/10.1016/j.biopsych.2009.03.006

Roozendaal, B., \& McGaugh, J. L. (2011). Memory modulation. Behavioral Neuroscience, 125, 797-824. https://doi.org/10.1037/ a0026187

Schoofs, D., Preuß, D., \& Wolf, O. T. (2008). Psychosocial stress induces working memory impairments in an $\mathrm{n}$-back paradigm. 
Psychoneuroendocrinology, 33, 643-653. https://doi.org/10. 1016/j.psyneuen.2008.02.004

Shields, G. S., Sazma, M. A., \& Yonelinas, A. P. (2016). The effects of acute stress on core executive functions: A meta-analysis and comparison with cortisol. Neuroscience \& Biobehavioral Reviews, 68, 651-668. https://doi.org/10.1016/j.neubiorev. 2016.06.038

Smeets, T., Jelicic, M., \& Merckelbach, H. (2006). The effect of acute stress on memory depends on word valence. International Journal of Psychophysiology, 62(1), 30-37. https://doi.org/10. 1016/j.ijpsycho.2005.11.007

Stauble, M. R., Thompson, L. A., \& Morgan, G. (2013). Increases in cortisol are positively associated with gains in encoding and maintenance working memory performance in young men. Stress, 16, 402-410. https://doi.org/10.3109/10253890.2013.780236

van Ast, V. A., Spicer, J., Smith, E. E., Schmer-Galunder, S., Liberzon, I., Abelson, J. L., \& Wager, T. D. (2016). Brain mechanisms of social threat effects on working memory. Cerebral Cortex, 26, 544-556. https://doi.org/10.1093/cercor/bhu206

Yaple, Z. A., Stevens, W. D., \& Arsalidou, M. (2019). Meta-analyses of the n-back working memory task: FMRI evidence of age-related changes in prefrontal cortex involvement across the adult lifespan. Neuroimage, 196, 16-31. https://doi.org/10.1016/j. neuroimage.2019.03.074

Ycaza Herrera, A., \& Mather, M. (2015). Actions and interactions of estradiol and glucocorticoids in cognition and the brain: Implications for aging women. Neuroscience \& Biobehavioral Reviews, 55, 36-52. https://doi.org/10.1016/j.neubiorev.2015.04.005

Zandara, M., Garcia-Lluch, M., Pulopulos, M. M., Hidalgo, V., Villada, C., \& Salvador, A. (2016). Acute stress and working memory: The role of sex and cognitive stress appraisal. Physiology \& Behavior, 164(Pt A), 336-344. https://doi.org/10. 1016/j.physbeh.2016.06.022

\section{Acknowledgments}

This study was part of a project on stress vulnerability conducted at the University of Trier, Germany. Dirk Hellhammer both initiated and supervised the project and stimulated further work on this topic through the first and senior author. We are thankful for his outstanding dedication and hope this work can show a bit of his enthusiasm for stress research.

\section{Funding}

This study was part of a project on stress vulnerability funded by the German Research Foundation, DFG grant HE 1013/21-1, conducted at the University of Trier, Germany.

\section{ORCID}

Jens C. Prüssner

(D) https://orcid.org/0000-0002-8582-2980

\section{Jens C. Prüssner}

Department of Psychology

University of Konstanz

Universitätsstr. 10

78457 Konstanz

Germany

jens.pruessner@uni-konstanz.de 